\title{
UNA ISLA Y DOS NACIONES: LAS RELACIONES DOMÍNICO-HAITIANAS EN EL MASACRE SE PASA A PIE DE FREDDY PRESTOL CASTILLO
}

An island and two nations: The Dominican-Haitian relations in The Slaughter Walk Pass by Freddy Prestol Castillo

\section{Hayden Carrón $*$}

Resumen: La frontera entre la República Dominicana y Haití ha sido tradicionalmente un lugar difuso, mítico y también trágico. A través de ella se cuentan historias de las poblaciones de dos países muy cercanos en composición étnica, pero muy diversos en el plano cultural. Esta porosa región de la isla fue testigo de la más sangrienta matanza étnica que ha tenido lugar en el Caribe durante el siglo Xx. En 1937, el dictador dominicano Rafael Trujillo ordenó el asesinato de todos los haitianos que se encontraran del lado dominicano de la frontera. Este horrendo episodio ha sido contado en numerosas ocasiones por escritores haitianos. Pero la única obra narrativa que de alguna manera expresa la versión dominicana de los acontecimientos, tuvo que esperar 36 años desde su redacción para ser para ser publicada en 1973. Se trata de la novela-testimonio El Masacre se pasa a pie de la autoría de Freddy Prestol Castillo.

En este artículo analizo esta obra literaria como una representación de las tortuosas relaciones entre dos naciones que por razones históricas están obligadas a compartir una misma isla.

Palabras clave: Literatura Dominicana, narrativa dominicana, isla, identidad dominicana, El masacre, Haití.

\footnotetext{
* Profesor de High Point University. Correo electrónico: hcarron@highpoint.edu
} 
Abstract: The border between the Dominican Republic and Haiti has traditionally been a complex, mythical and tragic place. This border tells stories about the people of two countries very close in ethnical terms but quite different in the cultural sphere. This porous region of the island witnessed the bloodiest ethnic cleansing of the Caribbean. In 1937, the Dominican dictator, Rafael Trujillo ordered the killing of all Haitians residing in the Dominican territory. This horrendous episode has been told in numerous occasions by Haitian writers. But the only literary work that, in someways, expresses the Dominican point of view had to wait 36 years to be published in 1973: the testimonial novel El Masacre se pasa a pie by Freddy Prestol Castillo.

In this article I analyze this literary work as a representation of the tortuous relationship between two countries that for historical reasons have to share the same island.

Keywords: Dominican literature, Dominican narrative, island, Dominican identity, the slaughter, Haiti.

\section{Introducción}

La historia de la República Dominicana y de Haití ha estado irremediablemente entrelazadas desde la época en que ambas fueron colonias de imperios rivales (Francia y España). La revolución Haitiana, que en 1804 logró convertir a la parte francesa de la isla en la primera nación negra soberana, precipitó los choques entre la élite esclavista dominicana (aún española) y los recién emancipados esclavos de la ex-colonia. La amenaza de que alguna de las potencias esclavistas de la época utilizara la parte española de la isla como puente para someter al pueblo haitiano, convenció a sus dirigentes de la necesidad de unificar la isla bajo la bandera de 
la República de Haití. Así, en 1822, aclamados por la mayoría de la población dominicana, el ejército haitiano tomó posesión del gobierno de Santo Domingo dirigiendo sus destinos hasta 1844, cuando la unión de los terratenientes y los intelectuales liberales dominicanos consiguió declarar la separación de las dos naciones.

Contrario a la historiografía oficial que presenta el período de unificación de la isla como una etapa oscura, llena de miseria y discriminación hacia lo dominicano, varios intelectuales han señalado que en dicha etapa pudo fácilmente cuajar un sentimiento nacional unitario entre las dos poblaciones debido a su reciente pasado colonial y a las características comunes. Hugo Tolentino lo explica de la siguiente manera:

Para ambas sociedades la encrucijada era realmente apropiada. Los factores que podian orientar a los habitantes de Santo Domingo hacia la buisqueda de una nacionalidad diferenciada de la baitiana no babian asomado aún. Es verdad que la nación tiene raices muy profundas en la bistoria, pero es preciso que maduren ciertas condiciones y aparezcan de manera definida ciertos elementos para que pueda integrarse. Pero eso no habia sucedido todavía en la parte oriental de la isla. Lo que el proceso señalaba era, a pesar de ciertas características de formación social diferente, una fusión de las dos comunidades en una sola nacionalidad (Tolentino, 1972: 119).

En realidad, gran parte de la población dominicana compartía los ideales de la revolución haitiana ya que sufría en sus propias carnes la rígida organización social que habían impuesto las clases dominantes donde el componente racial determinaba en gran medida la posición socioeconómica que ocuparía el individuo. Un ejemplo de cómo la población dominicana se identificaba con los dirigentes haitianos puede verse en que durante la primera mitad del siglo XIX, cuando España cedió la parte oriental de la isla a Francia y, los que luego dirigirían la independencia haitiana, se apresuraron a tomar posesión de la parte española, éstos fueron recibidos como héroes al pasar por las provincias del norte del país. Sobre 
este punto resulta ilustrativo una cita de Franklyn Franco que da la versión de una dama española residente en la colonia de Santo Domingo emigrada a Cuba debido a la sesión de la parte española de la isla:

Una dama de "alcurnia", Doña Francisca V alerio, relata en Santiago de Cuba al Presbitero doctor Francisco Gonzálezy Carrasco el espectáculo de la entrada de Toussaint a la ciudad de Santo Domingo el 3 de enero de 1801. Entre otras cosas dice: "entró el levantado Toussaint en nuestra ciudad, y solo faltó recibirlo debajo del Palio, porque según entiendo, a nuestro Monarca, no se le bubiera becho más” (Franco, 2003: 87).

Esas mismas provincias, un siglo después, serían testigo de la mayor matanza indiscriminada de haitianos que haya conocido la historia. Para entender el cambio de mentalidad de la población dominicana con respecto al vecino haitiano es necesario adentrarnos en el incansable martilleo de diversas narraciones identitarias propuestas por la élite dominicana en las cuales la desconexión entre lo dominicano y lo negro (lo haitiano) se enarbola como el elemento principal de la nacionalidad.

Durante el siglo XIX, la composición racial y cultural de los habitantes de la parte este de la isla tenían mucho más en común con los ideales y las políticas sociales de la nación haitiana que con la élite esclavista dominicana. El mejor ejemplo de esta afirmación lo encontramos en la fallida declaración de independencia encabezada por el intelectual José Núñez de Cáceres, en 1821, conocida como la "independencia efímera". Durante este episodio histórico, intelectuales y terratenientes se propusieron crear una República independiente que luego se uniera al proyecto que encabezaba Bolívar, pero manteniendo las principales políticas esclavistas de la administración imperial española. El poco apoyo de la mayoría de la población y la atracción que suscitaba la primera república negra del hemisferio occidental, dio lugar a la práctica invitación a que los haitianos tomaran las riendas del gobierno de la parte 
española de la isla. Es debido a esta unión en cuanto a proyectos nacionales entre las poblaciones de ambos países que la élite dominicana -conformada primoradialmente por criollos descendientes de la burocracia imperial española, que basaba su poder en la tenencia de la tierra y rasgos raciales europeos-, tuvo que plantearse el dilema de cómo convencer a una población mayoritariamente mulata de que tenía diferencias irreconciliables con la vecina República de Haití. Así, en la parte dominicana se creó el mito de que su composición racial era la mezcla entre los españoles y los indígenas, despreciando cualquier elemento de la raza negra en la conformación del discurso sobre la identidad nacional. El principal objetivo de este discurso es convertir al haitiano en el otro, el extranjero, alguien que "contamina" la pureza racial dominicana influenciándolo con su cultura africana, identificada con el caos y valores opuestos a los deseados para conformar una nación al estilo europeo o norteamericano. Como explica Doris Sommer:

From Sarmiento on, the liberal opposition between civilization and barbarism in Latin American thought has often implied a racial or a cultural opposition between whites and others'. (Sommer, 2004: 55).

Este dicurso identitario puede rastrearse desde el libro de 1785 del clérigo y abogado colonial Antonio Sánchez Valverde Idea del valor de la isla española y utilidades que de ella puede sacar su monarquía. En él, buscando defender a la élite de la colonia de los ataques con bases raciales de sus contrapartes europeos, acuña por primera vez la definición de etnicidad que definiría la identidad racial de la futura República Dominicana: "indispanos”. Es decir, la mezcla entre valientes conquistadores e indígenas taínos, dejando de lado cualquier influencia de los esclavos africanos en la conformación de la raza y la cultura dominicana.

\footnotetext{
1 "Desde Sarmiento en adelante, la oposición liberal entre civilización y barbarie en el pensamiento latinoamericano, muchas veces ha implicado una oposición racial o cultural entre blancos y otras razas".
}

Ciencia y Sociedad 2015; 40(2): 285-305 289 
Sin embargo, el principal y más influyente exponente del discurso indispano como base de la identidad dominicana fue el diplomático Manuel de Jesús Galván², que en su obra Enriquillo -considerada por Doris Summer como la ficción fundacional de la República Dominicana-, estiliza de tal manera el mito de la descendencia española e indígena del pueblo dominicano, que ha podido ser reproducido intensamente en todos los programas educativos del país.

Pero existe otro elemento que no se menciona mucho cuando se habla del surgimiento del prejuicio antihaitiano en la República Dominicana: las razones económicas. Con el establecimiento de los ingenios azucareros la mano de obra haitiana fue esencial para las élites dominicanas durante la mayor parte del siglo XX. Las condiciones de semiesclavitud que se vivían en los ingenios no hubieran sido toleradas por la población dominicana si no fuera por la demonización del haitiano hasta el punto de atribuirles rasgos animales. Toda esta discriminación, como explica Hugo Tolentino, tiene sus raíces en que la propuesta de un estado haitiano, con la abolición de la esclavitud, la repartición de tierras a los campesinos y el convencimiento de que solo conservando la soberanía era posible construir la nación, representaban una temible amenaza a los privilegios de la clase dominante dominicana.

Es preciso notar que será a partir del momento en que surge la libertad del esclavo y la igualdad del negro que el racismo contra los haitianos iniciará una desbocada carrera. Cuando Santo Domingo alcance su independencia, en 1844, la campaña racista se hará más violenta en

2 Manuel de Jesús Galván fue un político, diplomático y escritor dominicano que trabajó con el caudillo Pedro Santana para realizar la anexión de la República Dominicana a España. En 1865, ya derrotadas las tropas imperiales, se exilió a Puerto Rico donde siguió trabajando para el gobierno colonial español. En 1876 regresa al país nombrado nuevamente ministro de relaciones exteriores. Durante los últimos años de su vida dirigió las fracasadas negociaciones promovidas por el dictador Ulises Heureaux para arrendar la Bahía de Samaná a los Estados Unidos, a cambio de apoyo financiero y militar. Como escritor es conocido por su obra Enriquillo, la primera novela de largo aliento de un autor dominicano. 
la medida en que los sectores independentistas dominicanos se opongan a las maniobras de la oligarquía para anexar el país a una potencia extranjera, y, asimismo, en la medida en que Haití, bajo el temor de perder también su independencia, trate de oponerse a esos intentos. (Tolentino, 1972: 119).

Tanto para la clase dominante dominicana como para la del resto del continente Americano el surgimiento de una nación negra fue vista como una anormalidad que, además, atentaba directamente a los simientes - muchos de ellos raciales- en los que se pretendía basar el discurso identitario de las incipientes naciones. Pero no solo fueron las élites americanas las que se sintieron amenazadas por la revolución haitiana, las potencias coloniales entendieron que su dominio estaba en peligro, de triunfar los principios en que se basaba la revuelta, sobre todo la abolición de la esclavitud. Tolentino explica que:

En todo el mundo colonial basado en la esclavitud, se two la sensación de que algo se estaba resquebrajando peligrosamente. España reaccionó muy pronto contra la revolución haitiana. Ya en 1793 habia delineado, con el apoyo de sus posesiones coloniales de Cuba, México y Santo Domingo, todo un plan de guerra contra Haiti. Inglaterra, por su parte, mantenía en todo el Caribe una luch a enconada contra los efectos que iba produciendo la Revolución Francesa en la gran masa de esclavos y en los libertos. En la colonia de Santo Domingo la reacción no se hizo esperar. Cuando el gobernador Joaquin García se enteró de que Francia y España se encontraban en guerra y contempló el panorama insurreccional de la colonia vecina, sintió muy de cerca la Revolución Francesa. Bajo el miedo de la posibilidad del contagio, organizó seriamente en su colonia una cuarentena contrarrevolucionaria. (Tolentino, 1972: 112).

Es por esto que no ha de extrañar que las élites dominicanas, conscientes de que sus privilegios estaban en peligro en caso de triunfar la unificación de la isla, organizaran una agresiva campaña en detrimento de lo haitiano que aún sigue vigente en la actualidad dominicana. 


\section{La novela: historia y testimonio}

El Masacre se pasa a pie es una novela-testimonio que trata sobre uno de los períodos más oscuros de la dictadura de Trujillo: el asesinato de entre doce y veinte mil haitianos en la franja fronteriza y en la región Cibao en el año 1937. Con el propósito de "blanquear" la frontera e impedir la "invasión" de los negros haitianos (que generalmente eran requeridos para trabajar como peones en los ingenios azucareros, en la agricultura y en la ganadería), el régimen dispuso la puesta en libertad de presos con crímenes de sangre y reclutó entre las aldeas un gran número de "reservistas" que, armados y dirigidos por militares, formaron bandas cuyo único objetivo era asesinar a la mayor cantidad de haitianos que encontraran a su paso.

Un libro poco conocido de Rufino Martínez describe con detalles la masacre:

Una orden fue pasada por teléfono a los jefes de destacamentos de Santiago, Montecristi, Puerto Plata, Duarte y Barahona. Los que asombrados pidieron explicación sobre el caso, recibieron la intimidación de cumplir la orden, y nada más. En Santiago, el Comisionado del gobierno José Estrella, reunió su cuerpo de matones, al que se agregó un número de jóvenes, entre ellos estudiantes universitarios, y pasó a cucbillo a los haitianos residentes en Quinigua y demás campos cercanos. Las casas que habian construido en barrios de la ciudad, pasaron a ser propiedad de los oficiales del Comisionado. Los legitimos dueños fueron también exterminados. En Puerto Plata, una movilización de miembros del ejército, que se pusieron en pie de guerra, estuvo acompañada del secreto rumor de que babría una matanza. Al amanecer del día dos de octubre, en el llamado campo de experimentación (agricola), alcanzaban a ver los vecinos la matanza con garrote y puñal. En los lugares más apartados como Sosua, Cabarete y toda la costa siguiente hasta Nagua, el exterminio se hizo con arma de fuego, y fueron víctimas las mujeres, muchas encinta, y los niños, con la misma saña despiadada que los hombres. (Martínez, 1961: 156). 
La matanza duró varios meses pero tuvo su punto álgido en octubre de 1937, con la pasividad cómplice de la mayoría del pueblo dominicano y de los intelectuales orgánicos del régimen que veían los asesinatos como una gesta patriótica que defendiera la "cristiandad" y las costumbres "españolas" de la mayoría de la República, frente a la "incivilizada" raza y cultura haitianas. En realidad la dictadura solo tuvo que aprovechar los rencores de los dominicanos hacia sus vecinos haitianos provenientes de más de un siglo de narraciones identitarias que culpabilizaban al pueblo haitiano del atraso económico y social en que se encontraba el país.

Ante la matanza, la comunidad internacional reaccionó imponiendo sanciones al régimen de Trujillo, que argumentaba que se trataba de conflictos entre bandas dominicanas y haitianas, envueltas en el siempre engorroso problema de contrabando de mercancías por la poco vigilada frontera, y no un asunto racial. La intevención del gobierno norteamericano y la dócil coorperación del presidente haitiano Sténio Vincent, ayudaron a Trujillo a llegar a un acuerdo pagando una indemnización por los daños causados equivalente a 20 pesos por haitiano asesinado.

Para el pueblo haitiano el "kout kouto-a" (el apuñalamiento) como es conocida la matanza, ha estado muy presente tanto en la tradición oral como en obras narrativas. Quizá la más representativa de ellas es Le Peuple des Terres Melées (1989) de René Philoctète. Aunque la más conocida es sin duda The Farming of Bones (1998) de la escritora norteamericana de origen haitiano Edwige Danticat que obtuvo el premio al mejor libro norteamericano (American Book Award) en 1999, atestiguando la importancia y actualidad del tema para las relaciones domínico-haitianas.

Del lado dominicano hubo que esperar hasta la muerte del tirano Rafael Trujilo, en 1961, para comenzar a entrever las dimensiones de la masacre. Así, el texto de Prestol Castillo es la única obra literaria dominicana que se adentra en las vibraciones sociales que dieron lugar y permitieron el desarrollo de la matanza. 
El Masacre se pasa a pie se publicó en diciembre de 1973, treinta y seis años después de la redacción del primer borrador. En su introducción a la novela, el autor nos cuenta su impotencia como testigo mudo de tanta sangre y dolor. Escribió este libro -dicecomo catarsis al presenciar tanta crueldad, con el miedo a ser descubierto y la mirada de la tiranía en cada una de las páginas:

Tiranía es todo esto. La tiranía tiene el rostro como el de las estatuas: no ríe. La tiranía acogota con su mirada amarilla, peligrosa. (Cada vez que escribia, veía sobre mis pliegos furtivos los ojos amarillos de la tirania).

La tiranía es el tirano y todos los que no son el tirano. La tiranía es "Don Panchito el Matón" - aquel que agonizara catorce noches cantando como gallo, croando como rana, roncando como cerdo. También, el Cabo Sugilio: manos de tenazas, ojos profundos de animal de presa, actitud de leopardo. "Don Panchito el Matón" y el "Cabo Sugilio", estarian en todas partes. ¿No asecharian mi libro? ¿No espiarían mis pliegos?... ¡Ah no! ¡Don Panchito no sabe leer! ¡Tampoco sabe el cabo Sugilio! ¡Puedo escribir, tranquilo, en la noche! (Prestol Castillo, 1973: 10).

En 1937 Freddy Prestol Castillo se desempeñaba como fiscal en la perdida ciudad fronteriza de Dajabón. Ante la masacre, tuvo que elegir entre callarse y hacerse cómplice del crimen o escribir a escondidas para dejar un testimonio vivo de lo que realmente fue aquel genocidio. Por eso la novela se presenta no como un libro de ficción sino como una serie de retazos, reflexiones y situaciones yuxtapuestas que pretenden dar la visión de conjunto de lo que se vivió durante esos meses sangrientos. Esta presentación tan real y vivida de los hechos es, quizás, el mayor logro artístico de la obra. El lector se ve frente a una serie de escenas inconexas, personajes apenas esbozados, diálogos escuetos, cuyo único hilo conductor es la omnipresencia de la barbarie. 
La novela se unifica temáticamente en torno a dos metáforas que funcionan como pilares de andamiaje en el que se apoyan los retazos de historias encadenadas sin aparente conexión. Estas dos metáforas son: el corte y el río Masacre. "El corte" fue el nombre con que el pueblo dominicano bautizó la matanza de haitianos. La fuerza evocadora de este nombre nos remite a tres aspectos fundamentales de la sociedad dominicana y del conflicto de la inmigración haitiana. Primeramente, en el lenguaje de los productores de caña de azúcar, "corte" es equiparable a la zafra. Se refiere al extenuante trabajo que realizaban primero los esclavos durante la colonia y luego los haitianos. Es por esta actividad económica por la que gran parte de los inmigrantes haitianos cruzan anualmente la tenue frontera entre los países. Al llegar a los ingenios son mantenidos en un régimen de semiesclavitud continuamente amenazados con la deportación, rechazados por la mayoría de la población dominicana que los percibe como seres inferiores que "quitan el trabajo a los dominicanos".

La segunda significación de "el corte" es la que evoca la decapitación de los haitianos por "la mocha". El mismo instrumento agrícola que se utiliza para la zafra es el que utilizaron los asesinos para la matanza, de esta manera se presenta una correlación entre la necesidad económica que trae al haitiano a trabajar las tierras dominicanas y la muerte traidora a manos del instrumento que les provee su sustento cotidiano.

Por último, en un nivel más general y sociológico, "el corte" hace alusión a la fractura socioeconómica que pretendía el asesinato masivo de haitianos, tanto desde el punto de vista de limpieza étnica como de sumisión al poder de Trujillo de las regiones fronterizas. Lo cierto es que las provincias que limitan con las ciudades haitianas siempre han tenido un ritmo diferente al del resto de la nación. Lejos del poder central de la capital, abandonados a su suerte por los funcionarios estatales, durante la mayor parte de su historia han basado su economía en el comercio contrabandista con diversos 
grupos haitianos. En los inicios del trujillato, la libertad de movimiento que tenían las élites de las provincias fronterizas comenzó a verse como un problema de seguridad nacional. Así, la matanza de haitianos fungió como una fuerte señal a la población de las intenciones de poder totalizador del régimen. Al eliminar la fuerza de trabajo haitiana que permitía a los hateros la cría extensiva de ganado y la agricultura de subsistencia, Trujillo fue capaz de doblegar la relativa independencia con que se desarrollaba la región fronteriza del país.

En cuanto al río internacional Masacre, frontera natural entre República Dominicana y Haití, la simbología principal puede dividirse en dos aspectos. El primero sería el mismo nombre del río "Masacre", nombre predestinado a la barbarie y al enfrentamiento entre los dos pueblos. Y el segundo aspecto queda de manifiesto en el contraste entre las dos orillas. Del lado haitiano, muerte, sequía y hambre para sus pobladores, víctimas, también, de incontables tiranos que han arrasado el país. Del lado dominicano (para el haitiano), la única esperanza de supervivencia, aunque sea trabajando como esclavo en una nación que le desprecia.

El río Masacre es el testigo mudo no solo de la matanza que narra la novela, sino, mucho antes, de todo el conflicto racial y territorial entre las dos naciones:

El Masacre sigue corriendo, casi sin sonar de guijas. Río estrepitoso en sus cascadas de "La Garrapata" y "Loma de Cabrera", pasa cauto, como otro haitiano, frente al fortín dominicano. ¿Teme? El río sigue callado, hasta el Atlántico. (Prestol Castillo, 1973: 88).

\section{El antihaitianismo como identidad nacional}

A través del narrador de la novela, ese joven fiscal capitalino que se traslada a la fronteriza ciudad de Dajabón designado por el régimen de Trujillo y se encuentra como testigo de la matanza; podemos observar que, aunque existe un tono general de espanto 
en cuanto a la indiscriminada matanza, también se busca la justificación - $\mathrm{O}$ al menos la explicación- de la masacre como un hecho inevitable debido a la conflictiva relación entre los dos países.

Tres razones principales son presentadas en la novela como causas de la reacción del régimen de Trujillo para ordenar el genocidio. En primer lugar, el constante robo de ganado y ocupación de tierras dominicanas por parte de los haitianos. Incluso se presenta el personaje Hilarión, conocido como "el patú", que debido a sus poderes sobrenaturales era capaz de robar ganado en las posesiones mejor vigiladas del lado dominicano de la frontera. Según esta visión, tanto los ricos terratenientes como el pueblo llano se encontraban en constante amenaza por parte de bandas haitianas que saqueaban las propiedades, hecho que catalizó la violenta reacción contra ellos como una especie de escarmiento en defensa por tanto robo.

Sin limitar la extensión del robo de ganado, que llegó a ser de número considerable (aunque perpetrados no solo por los haitianos sino por bandas mixtas que se dedicaban a vender la carne y las pieles en los mercados del interior de los países), la mayoría de los haitianos residentes en las provincias fronterizas se eran jornaleros de terratenientes dominicanos, muchos de ellos amancebados con nacionales dominicanos y bastante integrados a la mezcla cultural que se vivía en esas provincias. La presentación del robo de ganado como justificación para la matanza indiscriminada de mujeres y niños, ha sido utilizada por el pensamiento nacionalista conservador para enmascarar como una "rabia popular incontenible" lo que realmente fue una planificada limpieza racial.

La segunda razón presentada es la supuesta haitianización de la frontera. Al igual que el régimen de Trujillo, nuestro narrador observa como la mayoría de las transacciones comerciales que se realizaban en la frontera se hacían con moneda haitiana; o el hecho de que una gran parte de la población se manejaba mejor con el creole que con el castellano para su comunicación cotidiana. Estas 
realidades remitían a la tan temida teoría dominicana de que las potencias extranjeras buscaban la unificación de la isla en una sola nación. Para preservar las diferencias identitarias entre las naciones era necesario - de acuerdo a estos planteamientos- "dominicanizar" la frontera dotándola no solo de presencia mayoritaria de dominicanos, sino sobre todo, evitando el constante asentamiento de los haitianos en el territorio y su consecuente amancebamiento con ciudadanos dominicanos. La contraparte del plan de "dominicanizar" la frontera la realizó el régimen poco después de terminada la matanza. A través de redadas en las principales ciudades de la República, el gobierno logró capturar a una gran cantidad de mendigos, enfermos mentales y delincuentes comunes y los envió a la frontera para que poblaran las tierras que fueron arrebatadas a los haitianos. El autor nos describe a estas huestes como "vagos" que no tenían la menor idea ni el deseo de cultivar la tierra o criar ganado.

A Dajabón venían ahora otros hombres. Eran los reclutados de los bajos fondos de las ciudades. También, campesinos sin tierras y sin trabajo agrícola, declarados "vagos" por sentencias. Estos hombres vendrían a asentarse en Dajabón y en las comarcas que le rodean. Los "vagos" vinieron traídos como reses en camiones del Ejército. Llegaron cuando se habían ido todas las reses y el viento de la montaña había escondido los restos de los ranchos y de los hombres, trocados en cal. (Prestol Castillo, 1973: 123).

Por último, el narrador hace un paralelismo entre la matanza de haitianos ordenada por el trujillato y las luchas por la independencia dominicana libradas contra el ejército haitiano. Un episodio histórico en particular le sirve al narrador para, en cierto modo, justificar la masacre contra los haitianos. Se trata de la retirada del general haitiano Jean Jacques Dessalines, quien en 1805 ordenó el asesinato y la quema de aldeas dominicanas (principalmente la ciudad cibaeña de Santiago de los Caballeros) como método para debilitar las huestes domínico-españolas que apresuraban su retirada. Esta desafortunada acción de Dessalines ha servido durante más de dos 
siglos de ejemplo de la brutalidad haitiana para los pensadores nacionalistas conservadores dominicanos. Sin embargo, Pedro Mir contextualiza ese momento histórico:

Pero la gravedad de estas consecuencias no se deriva, como lo plantean los historiadores convencionales y los sectores más retrógrados de nuestro pais que se sirven de ellos o que a ellos sirven, del hecho de que Dessalines cometiera tales o cuales acciones brutales e innecesarias. Aquéllos eran tiempos de extrema violencia y la situación, e inclusive las provocaciones que vinieron de esta parte, principalmente las de Serapio Reynoso, un nativo de color que servía a los franceses, pueden muy bien explicar $y$ cohonestar estas acciones. Los estudiosos que se libran de la pasión $y$ de la subjetividad no suelen ser tan condenatorios ni tan inquisidores a la hora de juggar a Dessalines desde la parte española. La gravedad de estas acciones se deriva del hecho fundamental de que pusieron de manifiesto que el caudillo baitiano no era tan poderoso ni la Francia metropolitana tan débil, como pareció en el momento de la victoria y de la proclamación de la Independencia. La retirada de Dessalines $y$ la llegada de recursos franceses cambiaron bruscamente la imagen épica del caudillo baitiano y expresaron que no era él la fuerza indiscutible y decisiva en los destinos de la isla. Semejante cambio en la situación hacia inevitable que cambiara la actitud de los habitantes de esta parte. (Mir, 1972: 176).

Es por esta dualidad al presentar la masacre de los haitianos en 1937 que Iván Grullón, autor de un documentado trabajo sobre la presentación de las relaciones domínico-haitianas en las novelas ElMasacre se pasa a pie y Mi compadre el general sol (1955), del escritor haitiano Jaques Stephen Alexis, nos dice que:

Por un lado, el narrador lamenta y denuncia como "bárbaro" la matanza de baitianos, pero por otra parte, evoca constantemente el pasado para explicar o justificar, quien sabe, el presente. No era necesario, repito, que Prestol Castillo insistiera tanto sobre la matanza del siglo pasado, pues con ellos excusa implicitamente a los asesinos del régimen trujillista. (Grullón, 1989: 23). 
Más modernamente, varios autores han debatido las intenciones de Prestol Castillo en la elaboración de su libro. Lydia Gil sostiene que, con su obra, Prestol Castillo realiza una apología de la actitud pasiva de la mayoría de la población durante "el corte", argumentando que la misma posición que toma el autor, de esconderse en lugar de hacer algo para evitar la matanza, lo convierte en cómplice de los horrores acaecidos (Gil, 1997). Por su parte, Kyle Echols utiliza la teoría de análisis discursivo de Foucault para redimir la figura de Prestol Castillo como un intelectual liberal que lucho contra un sistema dictatorial para establecer una sociedad menos racializada, aunque con limitadas concepciones teóricas, provenientes del mundo intelectual dominicano que le tocó vivir. (Echols, 2010).

Lo cierto es que en El Masacre... el autor dedica un largo espacio a contraponer la matanza de los haitianos que sobre la que escribe con episodios históricos de las luchas de independencia donde los soldados haitianos realizaron maniobras condenables. Un ejemplo este afán de contraponer las matanzas lo presenta a través de un sueño del narrador que lo retrotrae hacia la mitad del siglo XIX al escenario de la guerra de independencia dominicana. Despertando del sueño, el narrador nos dice:

Me sorprendió meditando sobre la historia presente que veía con mis ojos, escrita en caracteres de sangre, y aquella historia de impiedad, despotismo y crimenes cometidos por los haitianos, aprendida en las clases de historia de la infancia. (Prestol Castillo, 1973: 140).

En otra escena uno de los personajes justifica la matanza haciendo también alusión al pasado:

- iEstamos cobrándoles!

Así me decía Don David, el repartidor de las tierras, riendo plácidamente con su boca desdentada donde viaja el cigarro de comisura a comisura como un péndulo. 
- iNo me bable de Humanidad ni de yerbas de academia!... iEstamos cobrándoles! 'Es una deuda vieja! ;Hace un siglo estos mismos negros desangraron al pueblo dominicano, degollando hasta en las iglesias!... ¡Estamos cobrándoles!

Y miraba con odio sobre las montañas verdes, las montañas azules, las montañas estrujadas de Haití. (Prestol Castillo, 1973: 84).

Otro elemento que apoya la versión de Lydia Gil es la presentación que hace el narrador de los autores materiales de la masacre. Como ya hemos dicho el régimen de Trujillo liberó presos violentos acusados de los más diversos delitos en las cárceles del país y los envió a la frontera donde fueron estimulados por el botín y el alcohol a que dieran rienda suelta a sus instintos asesinos. Este procedimiento fue bastante común durante el régimen para luego poder justificar los hechos indicando que los habían cometido "civiles exaltados" y que el gobierno no tenía ninguna responsabilidad directa en los mismos.

En ElMasacre... Prestol Castillo presenta a los autores de la masacre como, por un lado, criminales y militares corruptos sedientos de sangre, y por otro, como campesinos reclutados forzosamente por las tropas del gobierno y obligados a servir de verdugos de personas inocentes a las que no conocían ni les guardaban ninguna animadversión. Los primeros autores mencionados son representados por el sargento Tarragona y el capitán Ventarrón, elementos del ejército dominicano que habían sido encomendados a dirigir a los reclutados para la matanza. También buscaban mejorar su posición social adueñándose del ganado y las posesiones de los campesinos haitianos asesinados. Ambos militares conocen el poder de exaltar la violencia que se le atribuye al ron en la cultura dominicana, por eso mantienen a sus reclutas en un estado permanente de borrachera para evitar las deserciones, los remordimientos o la insubordinación. 
Pero otros integrantes de la turba asesina de haitianos, eran campesinos que, acostumbrados al reclutamiento forzoso de uno $\mathrm{u}$ otro bando durante las incontables revoluciones que se rebelaban contra el gobierno central, solo buscaban seguir las órdenes para evitar ser acusados de insubordinación y fusilados por los militares. Estos campesinos tuvieron que echar mano del fuerte adoctrinamiento antihaitiano del que fue objeto (y en muchos sentidos todavía es objeto) la mayoría de la población dominicana. Ese odio recién estrenado, compuesto de una mezcla de complejo de superioridad racial y desquite por tanta miseria, unido al siempre utilizado argumento de que los inmigrantes "quitan el trabajo a los nacionales", conjugó uno de los capítulos más terribles del uso del sentimiento contra los haitianos como elemento aglutinador de la identidad nacional dominicana.

Resulta indudable que Prestol Castillo utiliza en su novela la misma ambivalencia hacia los hechos cometidos contra los haitianos que la mayoría de los intelectuales dominicanos, aún después de la muerte de Trujillo y el establecimiento de la democracia. Siendo la única obra dominicana que trata sobre este hecho histórico, El Masacre se pasa a pie se convierte en un documento histórico de suma importancia para entender las tensas relaciones domínicohaitianas.

\section{Referencias}

Alexis, J. (1976). Mi compadre el general sol. Santo Domingo: Editora Taller.

Danticat, E. (1998). The Farming of Bones. New York: Soho Press.

Echols, K. (2010). Foucault, Genocide, Criminology, and Eugenics: Reflections on the work of Freddy Prestol Castillo. AfroHispanic Review. (29.1 Spring 2010): 101-116. 
Franco, F. (2003) Los negros, los mulatos y la nación dominicana. Santo Domingo: Sociedad Editorial Dominicana.

Galván, M. (1964). Enriquillo: leyenda histórica dominicana. Nueva York: Las Américas Publishing Company.

Gil, L. (1997). "El masacre se pasa a pie" de Freddy Prestol Castillo ¿denuncia o defensa de la actitud dominicana ante "el Corte"? Afro-Hispanic Review (16.1 Spring 1997): 38-44.

Grullón, I. (1989). La matanza de los haitianos en El Masacre se pasa a pie y Mi compadre el general sol. Santo Domingo: Editora Universitaria UASD.

Howard, D. (2001). Coloring the nation. Colorado: Estados Unidos: Lynne Rienner Publishers.

Lozano, W. (1993). La cuestión haitiana en Santo Domingo. Santo Domingo: FLACSO.

Lozano, W. (2005). La paradoja de las migraciones. El Estado dominicano frente a la inmigración haitiana. Santo Domingo: Editorial UNIBE, Facultad Latinoamericana de Ciencias Sociales y Servicio Jesuita de Refugiados y Migrantes.

Lyon Johnson, K. (2003). Both Sides of the Massacre: Collective Memory and Narrative on Hispaniola. Mosaic: a Journal for the Interdisciplinary Study of Literature, 36(2), 75-93.

Martínez, R. (1961). Hombres dominicanos. Santo Domingo: Editora del Caribe.

Mir, P. (1972). Acerca de las tentativas históricas de unificación de la isla de Santo Domingo. En Pierre-Charles, G. (Ed.). Problemas dominico-baitianos y del Caribe. México: Universidad Nacional Autónoma de México.

Philoctète, R. (1989). Le peuple des terres melées. Port-au-Prince: H. Deschamps. 
Pierre-Charles, G. et al. (1972). Problemas dominico-batianos y del Caribe. México: Universidad Nacional Autónoma de México.

Prestol Castillo, F. (1973). El Masacre se pasa a pie. Santo Domingo: Editora Taller.

Price-Mars, J. et al. (1995). La República de Haití y la República Dominicana: diversos aspectos de un problema histórico, geográfico $y$ etnológico. Santo Domingo: Sociedad Dominicana de Bibliófilos.

Rosario Candelier, B. (1980). Trayectoria de la novela dominicana. Listín Diario, 7 de marzo, 12, 19 y 25 de abril y 2 y 9 de mayo de 1980.

Sánchez Valverde, A. (1947). Idea del valor de la isla Española. Ciudad Trujillo: Editora Montalvo.

Sommer, D. (2004). Ficciones fundacionales: las novelas nacionales de América Latina. Bogotá: Ediciones Fondo de Cultura Económica.

Tolentino, H. (1972). El fenómeno racial en Haití y en la República Dominicana. En Pierre-Charles, G. (Ed.). Problemas dominico-haitianos y del Caribe. México: Universidad Nacional Atónoma de México. 


\section{Hayden Carrón}

Es doctor en Literatura y Cultura Caribeña y Latinoamericana; Universidad Autónoma de Madrid (UAM), España; diplomado en Estudios Avanzados (Maestría) Literatura y Cultura Caribeña y Latinoamericana (UAM); licenciado en Filosofía y Humanidades por el Instituto Tecnológico de Santo Domingo (INTEC). Es profesor titular de Español, High Point University, USA (otoño 2007-presente).

Sus publicaciones más recientes son:

Carrón, H. (2013). Borrando la huella africana: la Sentencia 168-13 del Tribunal Constitucional Dominicano y la identidad nacional. Afro-Hispanic Review 32, 27-40.

Carrón, H. (2011). La nación como tragedia: el Pensamiento identitario dominicano en el siglo XIX. Colorado Revien of Hispanic Studies 8, 241-259.

Carrón, H. (2007). Dos de agosto. El Puro Cuento 2, 36-41.

Correo electrónico: hcarron@highpoint.edu

Recibido: 20/10/2014 Aprobado: 22/05/2015 
